\title{
PIGMENTED CREATINE DEPOSITS IN AMYOTROPHIC LATERAL SCLEROSIS CENTRAL NERVOUS SYSTEM TISSUES IDENTIFIED BY SYNCHROTRON FOURIER TRANSFORM INFRARED MICROSPECTROSCOPY AND X-RAY FLUORESCENCE SPECTROMICROSCOPY
}

\begin{abstract}
M. Z. KASTYAK, ${ }^{a, b}$
M. SZCZERBOWSKA-BORUCHOWSKA, ${ }^{\text {a } D . ~ A D A M E K, ~}{ }^{\mathrm{c}}$ B. TOMIK, ${ }^{c}$ M. LANKOSZ ${ }^{a}$ AND K. M. GOUGH ${ }^{b *}$

${ }^{a}$ Faculty of Physics and Applied Computer Science, AGH University of Science and Technology, Al. Mickiewicza 30, 30-059 Krakow, Poland

${ }^{b}$ Department of Chemistry, University of Manitoba, 360 Parker Building, Winnipeg, MB, R3T 2N2, Canada
\end{abstract}

${ }^{c}$ Neurological Department, Medical College, Jagiellonian University, ul. Botaniczna 3, 31-503 Krakow, Poland

\begin{abstract}
Amyotrophic Lateral Sclerosis (ALS) is an untreatable, neurodegenerative disease of motor neurons characterized by progressive muscle atrophy, limb paralysis, dysarthria, dysphagia, dyspnae and finally death. Large motor neurons in ventral horns of spinal cord and motor nuclei in brainstem, large pyramidal neurons of motor cortex and/or large myelinated axons of corticospinal tracts are affected. In recent synchrotron Fourier Transform Infrared microspectroscopy (sFTIR) studies of ALS CNS autopsy tissue, we discovered a small deposit of crystalline creatine, which has a crucial role in energy metabolism. We have now examined unfixed, snap frozen, post-autopsy tissue sections of motor cortex, brain stem, spinal cord, hippocampus and substantia nigra from six ALS and three non-degenerated cases with FTIR and micro-X-ray fluorescence (XRF). Heterogeneous pigmented deposits were discovered in spinal cord, brain stem and motor neuron cortex of two ALS cases. The FTIR signature of creatine has been identified in these deposits and in numerous large, non-pigmented deposits in four of the ALS cases. Comparable pigmentation and creatine deposits were not found in controls or in ALS hippocampus and substantia nigra. $\mathrm{Ca}, \mathrm{K}, \mathrm{Fe}, \mathrm{Cu}$ and $\mathrm{Zn}$, as determined by $\mathrm{XRF}$, were not correlated with the pigmented deposits; however, there was a higher incidence of hot spots $(\mathrm{Ca}, \mathrm{Zn}, \mathrm{Fe}$ and $\mathrm{Cu}$ ) in the ALS cases. The identity of the pigmented deposits remains unknown, although the absence of Fe argues against both erythrocytes and neuromelanin. We conclude that elevated creatine deposits may be indicators of dysfunctional oxidative processes in some ALS cases. (C) 2010 IBRO. Published by Elsevier Ltd. All rights reserved.
\end{abstract}

${ }^{*}$ Corresponding author. Tel: +1-204-474-6262; fax: +1-204-474-7608. E-mail address: kmgough@cc.umanitoba.ca (K. M. Gough).

Abbreviations: AD, Alzheimer disease; ALS, Amyotrophic Lateral Sclerosis; CNV, common copy number variants; FALS, familial Amyotrophic Lateral Sclerosis; FTIR, Fourier Transform Infrared microspectroscopy; H\&E, Hematoxylin and Eosin; NF, neurofilament; NSLS, National Synchrotron Light Source; PD, Parkinson disease; SALS, sporadic Amyotrophic Lateral Sclerosis; SFTIR, synchrotron Fourier Transform Infrared microspectroscopy; SOD1, copper/zinc superoxide dismutase; SRC, synchrotron radiation centre; XANES, X-ray absorption near edge structure; XRF, micro-X-ray fluorescence.
Key words: Amyotrophic Lateral Sclerosis, creatine, pigmented deposits, FTIR, XRF, synchrotron.

Amyotrophic Lateral Sclerosis (ALS) is a progressive neurodegenerative disorder affecting both upper (motor areas of cerebral cortex, cortico-bulbar tracts) and lower (spinal cord, brain stem) neurons, leading to death 2-5 years after disease onset (Rowland, 1998; Shaw, 2005). Most ALS cases are classified as sporadic (SALS); less than $10 \%$ are familial (FALS). Of the numerous mutations identified for FALS, $20 \%$ are copper/zinc superoxide dismutase gene defects. SALS and FALS are undifferentiated on clinical grounds, suggesting a common pathogenesis (Gonzalez de Aguilar et al., 2007; Bruijn et al., 2004; Rowland, 1998).

Previously, we had investigated the topographic and quantitative changes in the distribution and oxidation states of selected elements using micro-X-ray fluorescence (XRF) and X-ray absorption near edge structure (XANES), on CNS tissue from ALS, Parkinson disease (PD) and gliomas (Szczerbowska-Boruchowska et al., 2004; Chwiej et al., 2005; Tomik et al., 2006; Szczerbowska-Boruchowska, 2008). Elevated $\mathrm{Fe}, \mathrm{Cu}$ and $\mathrm{Zn}$ were found in neurons of the substantia nigra in PD compared to control, but no statistically significant differences were found in spinal cord tissue from three ALS cases compared to four control tissue samples (SzczerbowskaBoruchowska et al., 2004; Chwiej et al., 2005).

More recently, we have used synchrotron Fourier Transform Infrared microspectroscopy (sFTIR) to examine CNS tissue from ALS and nondegenerate cases previously studied with XRF. FTIR permits two-dimensional mapping of the principal biomolecules of tissue with sub-cellular spatial resolution (Dumas and Miller, 2003) and also enables investigation of differences in protein secondary structure, an important consideration for research in neurological disorders (Gallant et al., 2006; Rak, 2007a; Thomzig et al., 2004; Miller and Dumas, 2006). An unusual spectrum (Kastyak, 2005), was tagged as creatine from an FTIR database search (P. Dumas, SOLEIL Synchrotron, France, private communication). Subsequent spectral analysis by both FTIR and Raman spectroscopy confirmed its presence in ALS spinal cord tissue (Kastyak, 2005; Gallant et al., 2006; Chwiej, 2007); similar crystalline deposits have been identified in brain tissue from a trans- 
genic mouse model for $A D$ and autopsy tissue from $A D$ brain (Gallant et al., 2006; Rak et al., 2007b).

We are continuing this study, focusing on biochemical alterations detectable by FTIR in the CNS regions that exhibit neurodegeneration. Creatine kinase and its substrates, creatine and phosphocreatine, constitute an intricate cellular energy buffering and transport system connecting sites of energy production (mitochondria) with sites of energy consumption (Hemmer and Wallimann, 1993). Our goal is to evaluate the occurrence and distribution of creatine crystals in a more extensive set of ALS and nondegenerate CNS tissues, as we hypothesize that elevated levels of creatine indicate disturbed energy homeostasis and hypermetabolism. Entire sections $\left(1 \mathrm{~cm}^{2}\right)$ have been mapped at $25 \mu \mathrm{m}$ spatial resolution using a Perkin-Elmer Spotlight300 FTIR to locate creatine deposits, followed by higher spatial resolution SFTIR mapping, and XRF to test possible co-localization with metals implicated in ALS.

\section{EXPERIMENTAL PROCEDURES}

\section{Sample acquisition}

Tissue samples were taken during routine autopsies from six patients deceased from SALS with no positive familial history of the disease, herein denoted: $A 1$ to $A 6(58 \pm 10$ years, mean $\pm S D)$, and from a control group of three patients deceased due to non-ALS conditions, denoted: $\mathrm{C} 1$ to $\mathrm{C} 3$. The control group average age was $68 \pm 4$ years. All SALS patients were diagnosed as having clinically definite ALS according to EI Escorial Criteria (Brooks et al., 2000), and died due to respiratory failure, at the Neurological Department of the Jagiellonian University in Krakow. Sections were obtained from spinal cord, frontal lobe motor area of cortex, brain stem, hippocampus and region of pars compacta of substantia nigra. The brain tissue and spinal cord were taken from both groups (ALS cases and controls) with post-mortem autopsy delay time (time between death and fixation or snap freezing) $20.2 \pm 1.2 \mathrm{~h}$ (mean $\pm S D$ ) in ALS patients and $20.3 \pm 1.1 \mathrm{~h}$ in control group, without significant difference. The specimens were frozen at $-30{ }^{\circ} \mathrm{C}$ and sectioned by cryomicrotome at either 20 or $10 \mu \mathrm{m}$ thickness. The tissues have been sectioned very cautiously to avoid any contact between tissue section and medium: a drop of medium (Shandon CryomatrixTM Embedding Medium, with $10 \%$ polyvinyl alcohol and $4 \%$ polyethylene glycol) was placed on the metal holder and a block of tissue was gently affixed on top; having been frozen, the tissue was cut only from the upper side which had no contact with the medium.

From each sample, slices were taken for routine histopathological stain and for spectroscopic analysis. ALS has been confirmed accordingly to well known guidelines (Ince et al., 2008; Ellison et al., 2004) that include standard staining methods of Hematoxylin-Eosin, Luxol-fast Blue and anti-ubiquitin immunohistochemistry. In all cases, there was evidence of degeneration/ demyelination and marked loss of upper motor neurons, especially of pyramidal tracts, and lower motor neurons, in at least three anatomical regions. Some remaining neurons showed different forms of pathology regarded as more or less typical for ALS in at least in one anatomical region, including intraneuronal ubiquitin-positive "skein" inclusions or Bunina bodies.

Slices destined for FTIR and XRF analysis were mounted immediately onto thin polymer foil (AP1 foil (MOXTEK) of $0.15 \mu \mathrm{m}$ thickness or ultralene foil of $4 \mu \mathrm{m}$ thickness) and freeze-dried at $-20^{\circ} \mathrm{C}$. Each sample was examined under bright field illumination at up to $400 \times$ magnification; a photomontage was created to facilitate selection of IR mapping regions.

\section{IR data collection}

SFTIR spectra were collected at the Synchrotron Radiation Center (SRC), University of Wisconsin, and at the National Synchrotron Light Source (NSLS), Brookhaven National Laboratories, Upton NY. Individual reference spectra and IR maps were collected with a Spectra Tech Continuum IR microscope in transmittance mode from 4000 to $750 \mathrm{~cm}^{-1}$ at $4 \mathrm{~cm}^{-1}$ spectral resolution, using Happ-Genzel apodization. From 4 to 128 spectra were co-added, depending on the operating conditions, to achieve good signal to noise. No zero fill or spectral smoothing algorithms were employed. Spectra were saved in absorbance format.

Pure creatine monohydrate (Sigma, 95\% purity) was recrystallized from Millipore water evaporated onto a gold-coated silicon wafer; FTIR spectra were collected in reflectance mode.

Exploratory sFTIR maps were acquired first from control (C1) and ALS spinal cord sections (A1), to confirm the presence of creatine in an ALS sample. Spectral maps were collected in raster scan mode, with step size of 8 to $10 \mu \mathrm{m}$ and aperture of 10 to $12 \mu \mathrm{m}$.

Following the discovery of the pigmented, creatine-containing deposits, 26 complete tissue sections from ALS and control slices, selected variously from spinal cord, motor cortex, brain stem, hippocampus and substantia nigra, were mapped in entirety with a Perkin-Elmer Spectrum Spotlight 300 (NSLS). Spectra were recorded by illumination of sample with a globar IR source and detection by a scanning 16 element linear array. Pixels on the Spotlight microscope were fixed at $25 \times 25 \mu \mathrm{m}^{2}$, with a $25 \mu \mathrm{m}$ step size; depending on signal quality, 4 to 16 spectra were summed per step. Seventy-five maps including numerous pigmented creatine deposits in ALS tissue and comparable regions in control tissue were obtained at higher spatial resolution $\left(6 \times 6 \mu \mathrm{m}^{2}\right.$ to $10 \times 10 \mu \mathrm{m}^{2}$ pixels) with SFTIR at SRC and NSLS.

sFTIR maps were analyzed with Omnic/Atl $\mu$ s software (ThermoNicolet), on original, unprocessed spectra. The presence of creatine was evaluated on the basis of the area of the peaks at $1304 \mathrm{~cm}^{-1}\left(1309-1298\right.$, base line $\left.1317-1282 \mathrm{~cm}^{-1}\right)$ or 2800 $\mathrm{cm}^{-1}\left(1209-2787\right.$, base line $\left.2820-2760 \mathrm{~cm}^{-1}\right)$. Relative amount of creatine in a map was displayed with colors ranging from blue (low) to red (high). For a few spots, diffraction and scattering effects reduced spectral quality. Such artifacts indicate that the deposits are dense and probably at least twice as thick as the surrounding normal tissue. In those cases, the area of the creatine peak at $2800 \mathrm{~cm}^{-1}$ could be used effectively to illustrate the creatine presence. Although this peak is weaker, it also appears in a region free of other absorbances and, for such dense creatine deposits, was readily detectable. Spotlight 300 maps were processed and displayed in a similar manner, using the Spotlight v.1.5.1 software. The locations of creatine deposits identified by IR were examined under visible light microscopy, to evaluate possible association with pigmentation.

\section{XRF data}

Synchrotron X-ray fluorescence (sXRF) microprobe experiments were carried out at beamline X26A at NSLS. Eleven maps were acquired, seven from regions of ALS brain containing a total of eight pigmented creatine deposits, and four from comparable regions in control, including spinal cord (A1: three maps, $C 2$ ), cortex (A1, C1), brain stem (A4: two maps, C3) and hippocampus (A1, C1). Each sample was mounted at $45^{\circ}$ to the incident $X$-ray beam; XRF was detected with a 9-element Ge detector (Canberra, Meriden, CT, USA) oriented $90^{\circ}$ to the incident beam. A light microscope objective (M Plan Apo $5 \times$, Mitutoyo, Aurora, IL, USA) was coupled to a digital CCD camera for sample viewing in transmission or reflection geometries. Data were collected for 10 s/pixel; step sizes ranged from $5 \times 8$ to $10 \times 10 \mu \mathrm{m}^{2}$. The spectral peakfit algorithm in X26A_Plot was used to calculate peak areas 
in XRF spectra, to generate surface maps for $\mathrm{Na}$ (line $\mathrm{K}_{\alpha}$ ), $\mathrm{K}$ (line $\mathrm{K}_{\alpha}$ ), $\mathrm{Fe}$ (line $\mathrm{K}_{\alpha}$ and $\mathrm{K}_{\beta}$ ), Cu (line $\mathrm{K}_{\alpha}$ ), Zn (line $\mathrm{K}_{\alpha}$ ), Mn (line $\mathrm{K}_{\alpha}$ ).

Additional measurements were performed on the bending magnet beamline $L$ at HASYLAB/DESY; this site permits collection of the broad energy spectrum, and software permits conversion of raw data to masses per unit area. Topographic and quantitative elemental analysis of spinal cord tissue from one ALS case (A1) was performed, specifically targeting three pigmented creatine-containing deposits, where creatine was identified with SFTIR and deposits were already mapped with XRF at NSLS. The incident photon beam energy of $17 \mathrm{keV}$ enabled the analysis of elements with atomic number between 14 (Si) and $38(\mathrm{Sr})$. The beam was focused with polycapillary optics to $15 \mu \mathrm{m}$ diameter; measurements were carried out in air. The areas were mapped with a step of $20 \times 20 \mu \mathrm{m}^{2}$ and acquisition time of $10 \mathrm{~s} / \mathrm{pixel}$. Characteristic X-ray lines were measured with a $\mathrm{Si}(\mathrm{Li})$ detector (energy resolution $144 \mathrm{eV}$ at $5.9 \mathrm{keV}, 12.5 \mu \mathrm{m}$ thick Berylium window). Measurements of NIST standard reference materials (SRM, 1833 and SRM, 1832) were performed. For each map, the two-dimensional distribution of elements was obtained by analysis of each spectrum that included background subtraction, integration of the area under the peak of the $\mathrm{K} \alpha$ line corresponding to the chosen element and normalization of the net peak area of the element to the incident beam flux. Masses per unit area of elemental peaks were calculated from normalized fluorescence intensity for that element and the fluorescence sensitivity. The results were used for construction of a graphic matrix composed of the horizontal and vertical beam positions on the sample and the values of the masses of elements per unit area.

\section{RESULTS}

The primary goal of this study was to assess the presence of creatine in a more extensive set of ALS and control samples (Table 1). Exploratory sFTIR maps were acquired from control and ALS spinal cord sections; the presence of creatine in an ALS sample (A1) was confirmed. A typical spectrum of creatine in the ALS tissue (A1) is shown in Fig. $1 \mathrm{~A}$, along with the reference FTIR spectrum of pure creatine (Fig. 1B) and a spectrum of normal tissue (Fig. 1C). The pure creatine crystals exhibit numerous sharp, narrow peaks that are very distinct from the broad bands of tissue components (Gallant et al., 2006; Rak, 2007a; Gallant,

Table 1. Occurrence and distribution of creatine deposits

\begin{tabular}{clll}
\hline Class & Spinal cord & Motor cortex & Brain stem \\
\hline ALS & & & \\
A1 & $\checkmark \checkmark \checkmark \checkmark$ & $\checkmark \checkmark \checkmark \checkmark$ & $Q$ \\
A2 & - & - & $Q$ \\
A3 & - & - & $Q$ \\
A4 & $Q$ & $Q$ & $\checkmark \checkmark \checkmark \checkmark$ \\
A5 & $\checkmark \checkmark$ & $Q$ & $Q$ \\
A6 & - & $\checkmark \checkmark$ & $Q$ \\
Control & & & $Q$ \\
C1 & - & $\checkmark$ & $Q$ \\
C2 & - & - & - \\
C3 & $\checkmark$ & - &
\end{tabular}

$\checkmark \checkmark \checkmark \checkmark$ many large streak or globular creatine, many pigmented.

$\checkmark \checkmark$ many punctate creatine, non-pigmented.

$\checkmark$ few, punctate creatine; none pigmented.

- good sample, no creatine.

Q no sample.

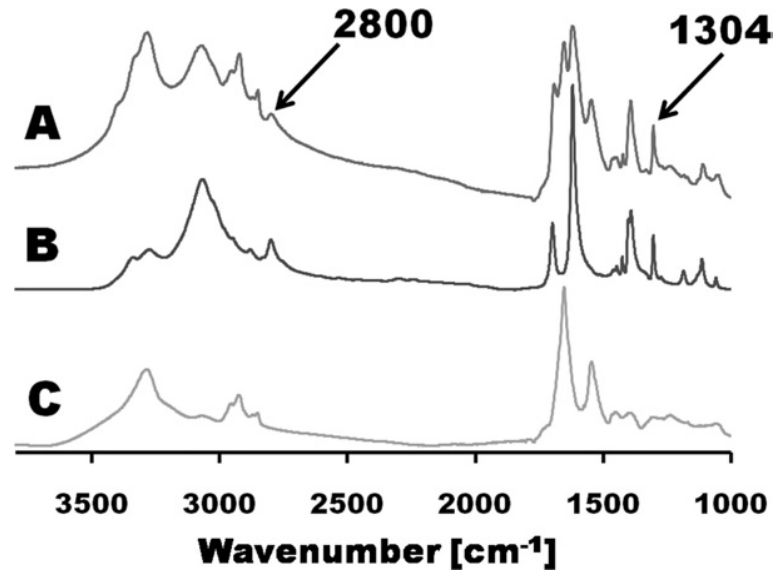

Fig. 1. FTIR spectra of CNS tissue with creatine deposit $(A)$, pure creatine $(B)$ and adjacent tissue $(C)$. Spectra have been vertically off set for clarity. Arrows indicate characteristic creatine peaks at 1304 $\mathrm{cm}^{-1}$ and $2800 \mathrm{~cm}^{-1}$.

2008). Such spectra are expected for crystalline creatine, where the high order and alignment of the relatively small molecules result in a few, sharply-defined vibrational modes. Precise band assignment has not been done, but some assignments have been attempted (Mitewa et al., 2002; Podstawka et al., 2007).

The principal tissue components are large biomolecules, thus the broad peaks reflect the general range of structures arising from the myriad functional group arrangements and distribution. SFTIR spectra of spinal cord tissue with creatine deposits contain all the major bands of pure creatine and of normal brain tissue. The areas under the creatine peak with maximum at $1304 \mathrm{~cm}^{-1}$, assigned to $\mathrm{CH}_{2} / \mathrm{NH}_{2}$ deformation modes (Podstawka et al., 2007) and peak with maximum at $2800 \mathrm{~cm}^{-1}$, assigned to a $\mathrm{CH}_{2}$ mode, were chosen to image the creatine distribution in tissue, as they occur in relatively non-absorbing regions of the tissue spectrum, thus they are readily distinguished.

Upon examination of the ALS spinal cord tissue under white light microscopy, unusual, amorphous dark features were discovered (Fig. 2A), some being rounder, 20-50 $\mu \mathrm{m}$ diameter and others larger and more elongated. The latter were usually present as streaks. The exploratory sFTIR maps of sample $A 1$ were acquired in an area containing two such pigmented features. The processed data showed that the IR signature of creatine could be detected only in the pigmented deposits (Fig. 2B).

Sections from areas affected in ALS, including eight from spinal cord (A1, A2, A3, two from A5, and $C 1-C 3$ ), seven from motor cortex (A1, A2, A3, A6 and C1-C3) and three from brain stem (two from A4 and one from $\mathrm{C} 3$ ), were completely mapped to determine the distribution and relative quantity of creatine deposits. Brain sections from areas not affected by ALS were also mapped: hippocampus (A1, A6 and C1) and substantia nigra (A3, A5 and C1-C3).

In Fig. 3, two complete spinal cord sections for $\mathrm{C} 1$ and $\mathrm{A} 1$, and the associated false-color maps, processed for creatine and for lipid, are shown. The control section (Fig. 3A) contains no creatine deposits (Fig. 3B) in gray or white 

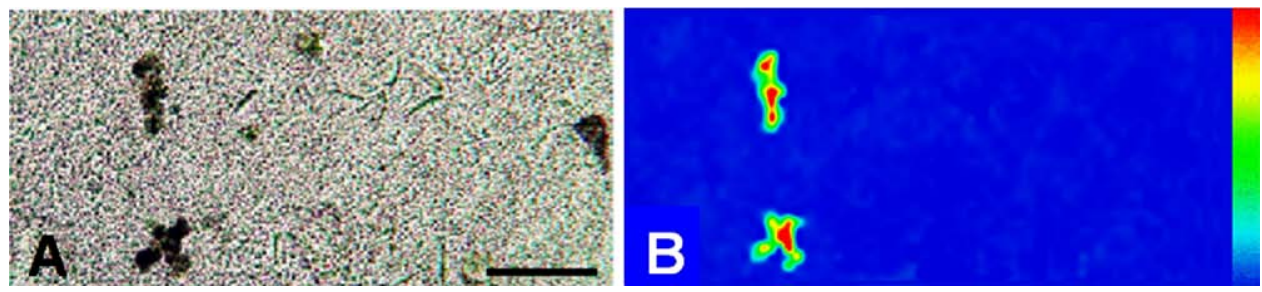

Fig. 2. Two creatine deposits in ALS spinal cord. (A) White light microscope image of tissue. Scale bar $100 \mu \mathrm{m}$. (B) FTIR map processed for creatine $2800 \mathrm{~cm}^{-1}$ peak. Synchrotron FTIR spectra were collected with $12 \times 12 \mu \mathrm{m}^{2}$ aperture, $10 \times 10 \mu \mathrm{m}^{2}$ step size, $4 \mathrm{~cm}^{-1}$ spectral resolution, Happ-Genzel apodization; processed for $2800 \mathrm{~cm}^{-1}$ peak area; false colour display range: $0-4.0$.

matter. After processing for lipid $\left(2854 \mathrm{~cm}^{-1}\right.$ peak area), the dorsal and ventral horns are readily apparent as protein-rich gray matter (Fig. 3C, dark grey), centered within the surrounding white matter (Fig. 3C, white). The ALS section (Fig. 3D) was found to contain 38 individually confirmed creatine deposits (Fig. 3E: bright yellow-red spots and streaks), distributed throughout both gray and white matter (Fig. 3F). Regions of demyelination (Swash et al., 1988) within the lateral corticospinal tracts are evident in Fig. 3F (arrows). Some streak-shaped creatine deposits were found to be several hundred $(100-500 \mu \mathrm{m})$ microns long (Fig. 3E); the shapes are suggestive of blood vessels. To investigate this, Hematoxylin and Eosin (H\&E) stained serial sections were examined for location of blood vessels relative to the creatine streaks, both pigmented and nonpigmented. The serially stained spinal cord section (Fig. $3 G$ ) is compared to the photo images, superimposed with the processed FTIR maps (Fig. 3H, I). While some blood vessels can be identified, they are randomly positioned relative to the creatine deposits, the majority of which are not in any proximity to such vessels.

Representative spectra corresponding to the major color gradations for creatine presence, from the PE Spotlight maps, are shown in Fig. 4. The strongest peaks are all visible in spectra corresponding to the upper end of the scale (red in Panel A, map A) and remain detectable to a
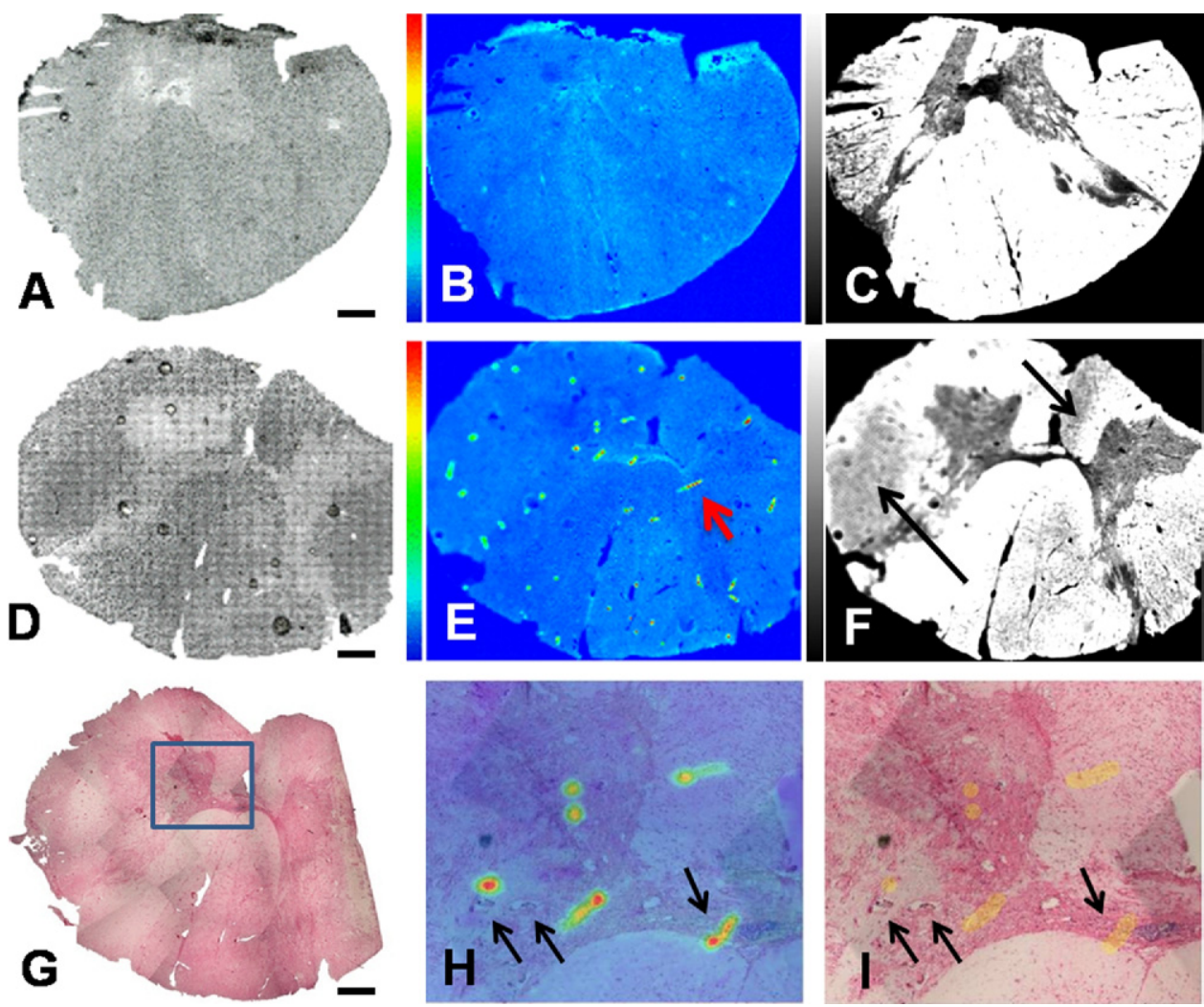

Fig. 3. Entire spinal cord images from (A-C) control and (D-G) ALS tissue. (A, D) White light microscope images of unstained tissue. (B, E) FTIR survey maps (PE Spotlight) maps processed for creatine $1304 \mathrm{~cm}^{-1}$ peak and (C, F) for lipid $2854 \mathrm{~cm}^{-1}$ peak. Maps processed for lipid delineate white from grey matter. Characteristic pallors, due to demyelination, are indicated by black arrows in (F). False colour display range $0.1-0.5(B, D)$ and 0.5-4.0 (C, E). (G) Hematoxylin and Eosin (H\&E) stain for ALS serial section. (H) region of H\&E stain section, delineated by blue box in (G), overlaid with FTIR map processed for creatine, as shown in (E). (I) region of H\&E stain section delineated by blue box in (G) shows creatine deposits (marked in yellow) and blood vessels. In (H) and (I), black arrows show blood vessel location. Scale bar $1000 \mu \mathrm{m}$. Red arrow in (F) identifies region shown in Fig. 4. 

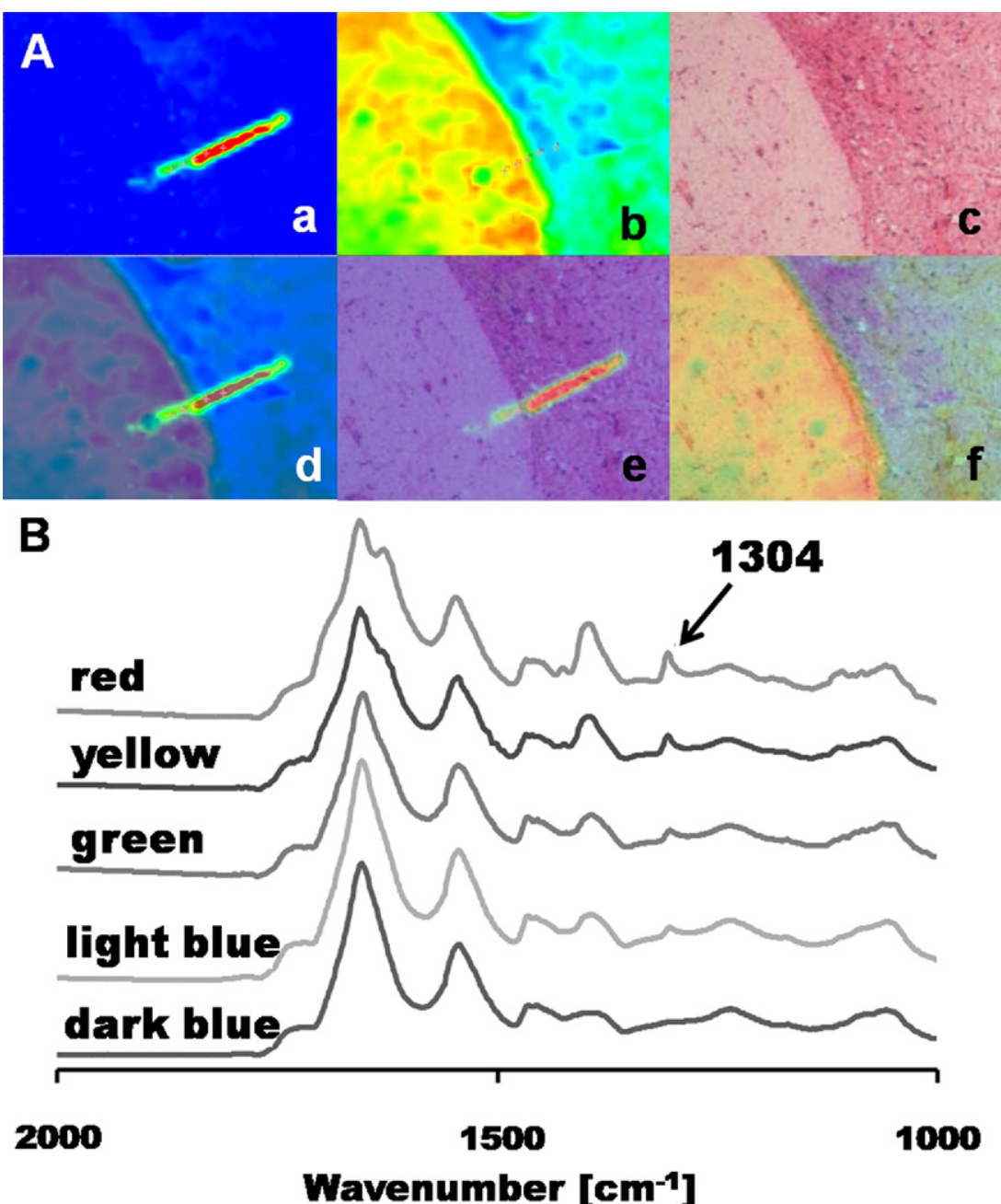

Fig. 4. Panel (A): Maps of creatine deposit indicated by arrow in Fig. 3, across edge of white and gray matter, processed for (a) creatine and (b) lipid and compared with (c) H\&E stain. Overlays of maps and H\&E stain $(d=a+b, e=a+c, f=b+c)$ clearly shows creatine concentration is higher in gray matter. Panel (B): Spectra corresponding to major creatine gradients: maximum (red) to zero (blue). Spectra have been vertically off set for clarity. False colour display limits: (a) $0.1-0.5$, (b) $0.5-4.0$.

lesser extent as relative concentration within the tissue decreases. Distinctively, the creatine deposits are highly localized; no traces of creatine are found elsewhere. Deposits located in gray matter were found to be larger, with a more intense signal (red in false colour scale display), than those in white matter (Fig. 4, Panel A). Examination of the tissue under visible light showed that about one quarter of the deposits were coincident with highly pigmented features. Data processing on the $1304 \mathrm{~cm}^{-1}$ peak showed that, while creatine was present in every pigmented spot observed in ALS brain tissues, non-pigmented creatine deposits were also present (Table 1). The brain stem section from case A4 (Fig. 5) composed mainly of gray matter (shown in grey in Fig. 5A), was found to contain some 65 creatine deposits (Fig. 5B, Spotlight map processed for creatine) of which 28 occurred as heavily pigmented streaks. Finally, a section from hippocampus of $A 1$ (Fig. 6A, photomicrograph) was found to contain two remarkable forked streaks of creatine (Fig. 6B). The creatine streaks are not pigmented. Total absorption intensity is normal (Fig. 6C); there are no scattering artifacts that would suggest abnormal thickness, shape or density; they do not correspond to any of the morphological features revealed by processing the FTIR spectra for lipid. E\&H staining does not show any morphological feature of this shape.

In the four NSLS XRF maps of control brain, elemental distribution was low and evenly distributed, with the exception of one spinal cord map, where elemental levels in a neuron exceeded that of surrounding tissue. The seven NSLS XRF maps of ALS spinal cord, brain stem and cortex revealed a few random hot spots of $\mathrm{Ca}, \mathrm{Cu}, \mathrm{Fe}$ and $\mathrm{Zn}$. Two areas of ALS spinal cord sample (A1) containing creatine deposits were mapped at HASYLAB. The visible image of one of the mapped regions and corresponding elemental distributions for $\mathrm{K}, \mathrm{Ca}, \mathrm{Fe}, \mathrm{Cu}$ and $\mathrm{Zn}$ as matrix graphic visualization are shown in Fig. 7. The pigmented deposits are those mapped with sFTIR (Fig. 2). The HASYLAB results, which can be displayed as masses per unit area, confirm the NSLS data, showing several hot 

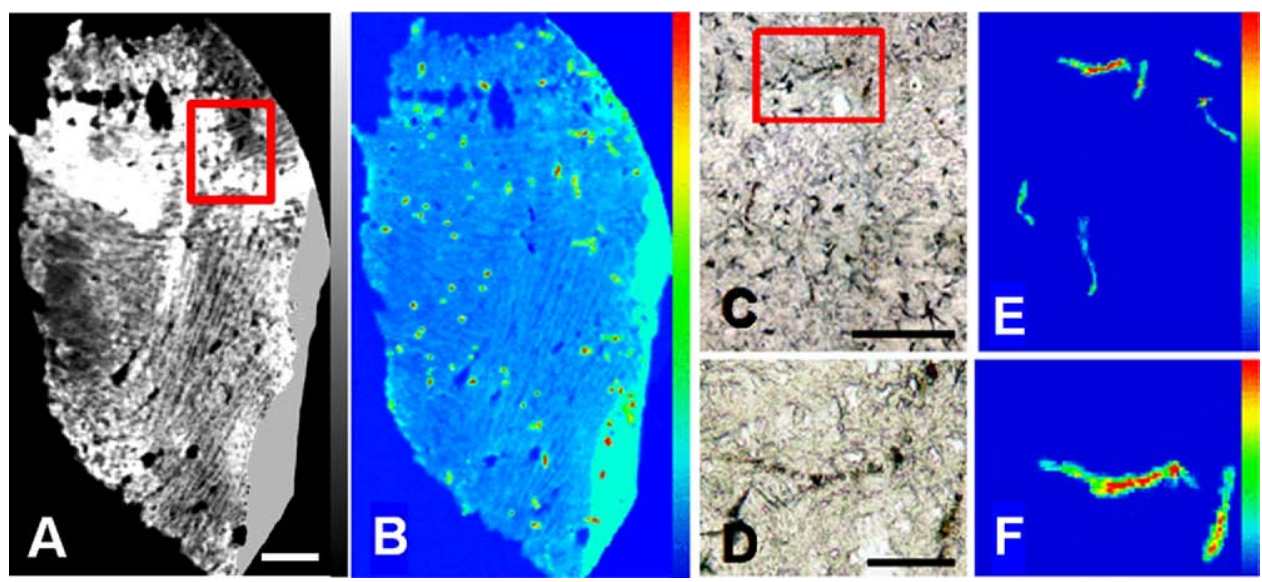

Fig. 5. Higher spatial resolution sFTIR maps demonstrate that creatine is completely identified and delineated with PE Spotlight large survey FTIR maps of ALS brain stem. (A) FTIR map processed for lipid reveals tissue morphology: white and grey are shown accordingly in grey scale as white and grey. (B) Spotlight 300 map, $25 \times 25 \mu \mathrm{m}^{2}$ pixel and step size, $4 \mathrm{~cm}^{-1}$ spectral resolution, four scans/pixel, processed for creatine $1304 \mathrm{~cm}^{-1}$ peak area. (C) region selected for sFTIR mapping, delineated by red box in (A). (D) region for sFTIR map delineated by red box in (C). (E) sFTIR map of region (C), recorded with $12 \times 12 \mu \mathrm{m}^{2}$ aperture, $10 \times 10 \mu \mathrm{m}^{2}$ step size, $4 \mathrm{~cm}^{-1}$ spectral resolution, four scans/pixel, processed for creatine. (F) sFTIR map of region C, recorded with $8 \times 8 \mu \mathrm{m}^{2}$ aperture, $6 \times 6 \mu \mathrm{m}^{2}$ step size, $4 \mathrm{~cm}^{-1}$ spectral resolution, 32 scans/pixel; processed for creatine. Scale bar $=1000 \mu \mathrm{m}$ (A, B); $100 \mu \mathrm{m}$ (C to F). False colour display limits for lipid: 0.5-4.0, for creatine: (B) $0.1-0.5(E, F) 0-2.0$

spots randomly located 20 to $50 \mu \mathrm{m}$ from the pigmented creatine deposits. The distribution of elements in Fig. 7 was heterogeneous and without pattern; the few hot spots of $\mathrm{K}, \mathrm{Zn}$ and $\mathrm{Cu}$, outlined by dashed black boxes, seem to be random and do not correlate with the shape of the deposit. Similar random hot spots were observed for all NSLS and HASYLAB XRF maps of the six other pigmented deposits (data not shown).
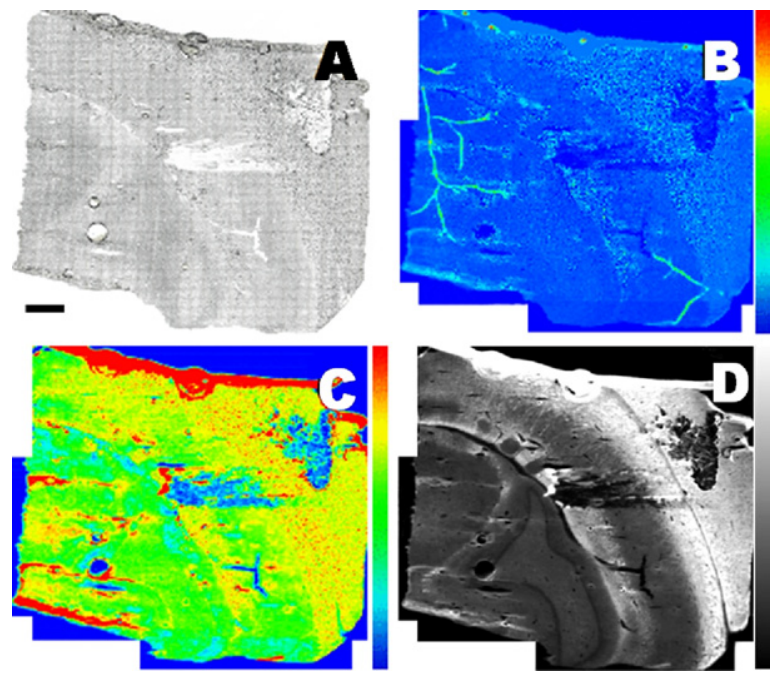

Fig. 6. Non.-pigmented creatine deposits are not thicker than adjacent tissue and do not correlate with grey and white matter morphology (A) Light microscope image of ALS hippocampus sample mapped with PE Spotlight. Scale bar $1 \mathrm{~mm}$. (B) FTIR map processed for creatine, $1304 \mathrm{~cm}^{-1}$ peak area, reveals long, river-shaped deposits. (C) Chemigram (total area under each spectrum from 999 to $3999 \mathrm{~cm}^{-1}$ ) illustrates sample thickness. (D) FTIR map processed for lipid, corresponds with sample morphology and shows creatine is almost exclusively located in grey matter. False colour display range: $(B)$ creatine: 0.1-0.4 (C) Chemigram: 0-300 and (D) lipid: 0.5-4.0.

\section{DISCUSSION}

ALS is a multietiological disorder in which oxidative stress (Trushina and McMurray, 2007), axonal transport (Strong et al., 2005) and cytoskeletal dysfunction related to phosphorylation (Yang et al., 2003; Strong et al., 2006), glutamatergic excitotoxicity accompanied with an increase in intracellular calcium leading to deranged mitochondrial function (Spreux-Varoquaux et al., 2002), microglial and astrocytic proliferation and abnormal protein aggregation (Strong et al., 2005; Wilson et al., 2001) play crucial roles in neuronal degeneration. Fifteen different basic mutations and 130 variants have been identified in FALS cases (Strong et al., 2005; Roberts et al., 2007), but these account for less than $10 \%$ of all ALS. Genome-wide screening of 810 individuals (406 with sporadic ALS) did not reveal any common copy number variants (CNV) in the ALS cases, although the number of CNV was significantly elevated overall, suggesting that multiple rare deletions may be also factor (Blauw et al., 2008).

Here, we report the discovery of pigmented and nonpigmented creatine-rich deposits in CNS tissues from two cases of Sporadic ALS. The spatial resolution of SFTIR microspectroscopy is generally $6-10 \mu \mathrm{m}$. The spectral identification of creatine is clear cut (Fig. 1). The deposits are in the range of $10-50 \mu \mathrm{m}$ and up, and are easily detectable. The large, often deeply pigmented, deposits (Fig. 2) have been found exclusively in two of the ALS cases, in all three regions affected by neurodegeneration: spinal cord, brainstem and motor cortex. Demyelination is evident in the lateral corticospinal tracts (Fig. 3F), a characteristic feature of some ALS cases (Swash et al., 1988). The creatine deposits detected in this section are predominantly located in the grey matter and in these regions of demyelinated white matter. A few punctuate non-pig- 


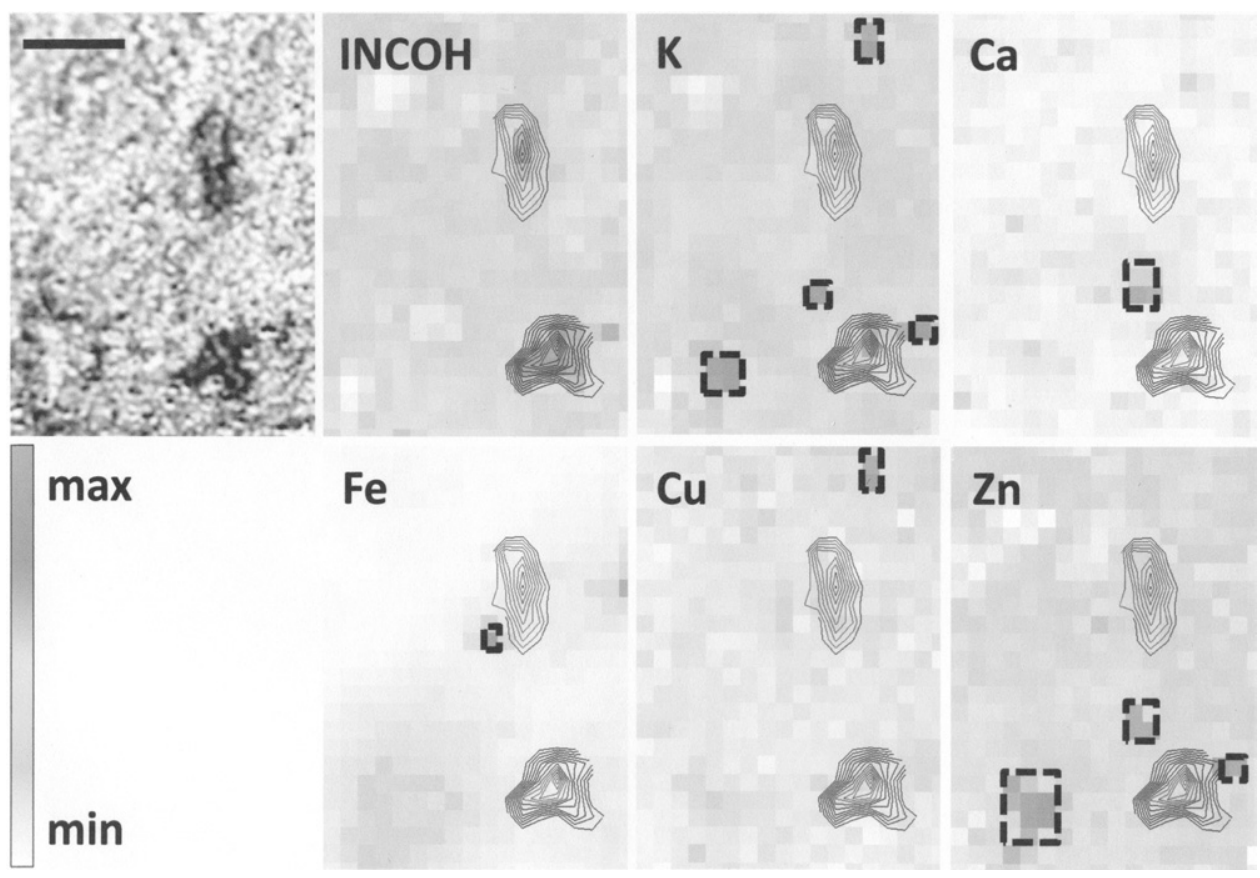

Fig. 7. XRF maps of selected elements obtained for ALS spinal cord sample region containing creatine deposits (white light image on the left top corner). Contour map created from incoherent scattering (INCOH) data indicate locations of dense creatine deposits (false colour display range: 1900-3900 for INCOH). There is no co-localization between creatine deposits and elements $\mathrm{K}, \mathrm{Ca}, \mathrm{Fe}, \mathrm{Cu}$ and $\mathrm{Zn}$. Elemental hot spots are outlined with dashed black line. Scale bar $100 \mu \mathrm{m}$. False colour display range for two dimensional distributions of masses per unit are of elements $\mathrm{K}$ : 3.80-8.30; Ca: 0.90-5.40; Fe: 0.05-0.65; Cu: 0.002-0.022; Zn: 0.026-0.058.

mented deposits no greater than one pixel in size are also just detectable.

Significantly perhaps, no pigmented deposits were found in the hippocampus or substantia nigra of these two ALS cases. Numerous punctate deposits (FTIR creatine signature detectable across a few pixels) were detected in two of the remaining four ALS cases studied, and in nondegenerate CNS tissue (Table 1), similar to those found in normal aged brain (Gallant et al., 2006). Thus, we distinguish between the small, punctate deposits and the large, often pigmented, deposits; while the former may be significant, we hypothesize that the latter are related to the diseased state.

It is not surprising that creatine deposits have not been reported before, since all commonly employed staining protocols involve numerous solvent treatments that would wash away small, soluble molecules like creatine. No sample preparation is required for FTIR, beyond snap-freeze and cryosectioning, thus creatine is preserved in situ. While the creatine is now crystalline, the condition in vivo cannot be determined from these samples.

Numerous inclusions and aggregates have been observed in ALS cases; their composition and origin are not yet fully understood. Aggregate formation may occur in the primary disease pathogenesis underlying neurotoxicity or in a secondary stage reflecting neuronal dysfunction; some aggregates might represent a cellular defense mechanism (Wood et al., 2003). Among these pathological hallmarks are intraneuronal inclusions, including Bunina bodies (Bunina, 1962), ubiquinated neuronal inclusions, dystrophic neurites and superficial linear spongiosis (Wilson et al.,
2001; Xiao et al., 2008), skein-like compact ubiquinated inclusions, hyaline conglomerate neurofilament inclusions, axonal spheroids and mutant copper/zinc superoxide dismutase (SOD1) aggregates in FALS (Strong et al., 2005; Wood et al., 2003). Extra- and intraneuronal tau inclusions have been also found (Yang et al., 2003; Chou et al., 1998); neurofilament (NF) aggregates may be associated with the stoichiometry of the low-high molecular weight NF (Strong et al., 2007). Given the broad variety of known inclusions and the variety in our cases studies (Adamek et al., 2002), the presence of creatine-containing pigmented deposits is postulated to be another sporadically-occurring aggregate requiring further investigation.

All attempts to process FTIR data on other spectral features failed to produce spectroscopic evidence of colocalization between the creatine deposits and any other biochemical tissue components. The analysis was occasionally hindered by the poor quality of individual spectra from some of the denser deposits, but the vast majority of creatine-containing spectra were of excellent quality and showed only the normal profile for distribution of protein, lipid, phosphate and sugar, as seen in the remaining spectra across the tissue.

The pigmented deposits often appear as streaks (Figs. 3-5), strongly reminiscent of blood vessels or capillaries, which could explain the coloration. Co-localization could be expected since creatine is taken up continuously through the blood-brain barrier by creatine transporter (Lunardi et al., 2006; Ohtsuki et al., 2002). Visual comparison of the processed map images with the H\&E stained sections did not reveal any such correlation (Fig. 3, G-I), 
but analysis for $\mathrm{Fe}$ would be more informative. Alternatively, the pigment might be due to neuromelanin, which is responsible for the color in neurons of substantia nigra. Again, analysis for metals would be informative, since neuromelanin is a strong chelating agent (Gaeta and Hider, 2005; Double et al., 2000; Zecca et al., 2003). The large, non-pigmented streak of creatine detected in the hippocampus of case A1 (Fig. 6) may be the result of elevated inflammatory state throughout the system; the shape might be due to creatine having pooled into a single extended crystalline deposit upon sectioning.

The two-dimensional distribution of $\mathrm{K}, \mathrm{Ca}, \mathrm{Fe}, \mathrm{Cu}, \mathrm{Zn}$, determined by synchrotron XRF at HASYLAB/DESY on two of the typical deeply pigmented creatine-containing deposits, show no abnormal elevation of any elements within the pigmented deposits (Fig. 7). A few hot spots are apparent for each of these elements, but these are randomly distributed across the tissue. The elemental distributions from the two HASYLAB analyses were consistent with the experiments conducted at NSLS. Since control samples did not have large creatine deposits, comparable regions were mapped from cortex (C1), spinal cord (C2), brain stem (C3) and hippocampus (C1); these showed normal, slightly heterogeneous distribution of all elements. Several locally-elevated spots of $\mathrm{Ca}, \mathrm{Fe}$ and $\mathrm{Zn}$, similar to those in Fig. 7, were observed in all ALS cases, in all tissue regions sampled, including hippocampus, which is unaffected in ALS. Elemental "hot spots" are not co-localized with pigmented creatine deposits. Their existence is interesting, since none of the ALS cases studied here were FALS, or identified in any way as belonging to the SOD1 mutation group of diseases. We interpret the absence of elements such as $\mathrm{Fe}, \mathrm{Cu}$ and $\mathrm{Zn}$ to mean that neither blood nor neuromelanin can explain these deposits.

Creatine is present in normal brain tissue where the creatine/phosphocreatine system acts as a shuttle of high energy phosphates, helping to maintain ATP homeostasis but, under normal physiological conditions, there is no apparent reason for the existence of large reservoirs. Some creatine is synthesized endogenously in the developing brain and localized in distinct cell populations (Braissant et al., 2001) and also crosses the blood-brain barrier (Lunardi et al., 2006). The mitochondria may help to regulate the intracellular distribution of creatine (Watzel et al., 2002). Creatine and phosphocreatine can diffuse across the mitochondrial membrane through porous channels (Schlattner et al., 2006) and help to buffer intracellular energy stores (Klivenyi et al., 1999).

The creatine deposits discovered here could be a marker of metabolic changes correlated with some forms of ALS. Dysfunctional mitochondria are well known feature of ALS, even at early stages (Kong and Xu, 1998; Mattson et al., 2008). A recent study found hyperlipidemia, particularly an elevated LDL/HDL ratio, in $45 \%$ of ALS patients but only $16 \%$ of controls (Dupuis et al., 2008) even though ALS patients were not obese. The elevated ratio was found to be a significant predictor for increased survival of more than 12 months in ALS patients. It is possible that elevated creatine levels play a role in this hypermetabolism.
Creatine supplementation has been found to offer neuroprotection against oxidative stress in SOD1 mice (Klivenyi et al., 1999; Klivenyi et al., 2004), while a human clinical trial of creatine monohydrate showed a trend toward increased survival (Rosenfeld et al., 2008). Recent trials on combined dietary therapies that include creatine (Tarnopolsky and Safdar, 2008; Benatar, 2008; Shefner et al., 2004) indicate the promise and the complexity of such supplementation strategies. Such a controlled study is beyond the scope of the present work. Our findings should not be construed as an indicator either for or against creatine supplementation at any stage of the disease.

As yet, no specific biological markers for ALS have been identified; diagnosis depends on the recognition of a characteristic clinical constellation that includes both upper and lower motor neuron degeneration and progressive motor dysfunction. We have found creatine deposits in both white and gray matter in the spinal cord, brainstem and motor cortex tissue where loss of motor neurons and demyelination are observed (Sandyk, 2006). Four of the six ALS cases had at least some level of elevated creatine; two of the cases exhibited pigmentation in $25-50 \%$ of the deposits. While the ALS cases showed numerous abnormal elemental concentrations, these were not associated specifically with the pigmented deposits. Although the sample size is small, the number of positives is striking, and the possibility that the six ALS cases encompass different forms of ALS differing from each other with particular pathogenesis cannot be excluded. This discovery of pigmented creatine deposits in ALS post mortem tissue may be another important step toward understanding the relationship between ALS and specific cellular and molecular processes in human CNS energy homeostasis and hypermetabolism.

Acknowledgments-This work was supported by NSERC, CIHR and CIHR ITMHRT, the Ministry of Science and High Education (Warsaw, Poland) grants: DESY/304/2006 (2007-2009; Ministry of Science and High Education, Warsaw, Poland); The European Community-Research Infrastructure Action under FP6 "Structuring the European Research Area" Programme (through the Integrated Infrastructure Initiative "Integrating Activity on Synchrotron and Free Electron Laser Science"); Contract RII3-CT-2004506008 (IA-SFS). We are grateful to Dr. Robert Julian, SRC Madison; Randy Smith, Ariane Kretlow, Dr. Lisa Miller, at U10B IR beam line and Dr. Antonio Lanzirotti at X26A beam line, NSLS Brookhaven for technical support. We thank $M$ Gallant, $R$ Wiens, Drs. M Rak, G Sivakumar J Chwiej and A Szeghalmi for their assistance.

\section{REFERENCES}

Adamek D, Tomik B, Pichor A, Kaluza J, Szczudlik A (2002) The heterogeneity of neuropathological changes in amyotrophic lateral sclerosis. A review of own autopsy material. Folia Neuropathol 40(3):119-124.

Benatar M (2008) Lost in translation: treatment trials in the SOD1 mouse and in human ALS. Neurobiol Dis 26(1):1-13.

Blauw HM, Veldink JH, van Es MA, van Vught PW, Saris CGJ, van der Zwaag B, Franke L, Burbach JPH, Wokke JH, Ophoff RA, van den Berg LH (2008) Copy-number variation in sporadic amyotrophic 
lateral sclerosis: a genome-wide screen. Lancet Neurol 7(4): 319-326.

Braissant O, Henry H, Loup M, Eilers B, Bachmann C (2001) Endogenous synthesis and transport of creatine in the rat brain: an in situ hybridization study. Brain Res Mol Brain Res 86:193-201.

Brooks BR, Miller RG, Swash M, Munsat TL (2000) El Escorial revisited: revised criteria for the diagnosis of amyotrophic lateral sclerosis. Amyotroph Lateral Scler Other Motor Neuron Disord 1: 293-299.

Bruijn LI, Miller TM, Cleveland DW (2004) Unraveling the mechanisms involved in motor neuron degeneration in ALS. Annu Rev Neurosci $27: 723-749$.

Bunina TL (1962) On intracellular inclusions in familial amyotrophic lateral sclerosis. Zhurnal nevropatologii i psikhiatrii imeni S.S. Korsakova (Moscow, Russia) 62:1293-1299.

Chou SM, Taniguchi A, Wang HS, Festoff BW (1998) Serpin-serine protease-like complexes within neurofilament conglomerations of motoneurons in amyotrophic lateral sclerosis. J Neurol Sci 160 (Suppl 1):S73-S79.

Chwiej J (2007) PhD thesis: Promieniowanie synchrotronowe w badaniach składu pierwiastkowego oraz związkǒw organicznych w komǒrkach nerwowych dla wybranych schorzeń neurodegeneracyjnych. University of Science and Technology, Krakow, Poland.

Chwiej J, Szczerbowska-Boruchowska M, Wójcik S, Lankosz M, Chlebda M, Adamek D, Tomik B, Setkowicz Z, Falkenberg G, Stęgowski Z, Szczudlik A (2005) Implementation of X-ray fluorescence microscopy for investigation of elemental abnormalities in central nervous system tissue. J Alloy Comp 401:184-188.

Double KL, Zecca L, Costi P, Mauer M, Griesinger C, Ito S, BenShachar D, Bringmann G, Fariello RG, Riederer P, Gerlach M (2000) Structural characteristics of human substantia nigra neuromelanin and synthetic dopamine melanins. J Neurochem 75(6): 2583-2589.

Dumas P, Miller $L$ (2003) The use of synchrotron infrared microspectroscopy in biological and biomedical investigations. Vib Spectrosc 32:3-21.

Dupuis L, Corcia P, Fergani A, Gonzalez De Aguilar JL, BonnefontRousselot D, Bittar R, Seilhean D, Hauw JJ, Lacomblez L, Loeffler JP, Meininger V (2008) Dyslipidemia is a protective factor in amyotrophic lateral sclerosis. Neurology 70(13 Pt 1):1004-1009.

Ellison D, Love S, Chimelli L, Harding BN, Lowe J, Vinters HV (2004) Neuropathology. A reference text of CNS pathology, 2nd ed. New York: Mosby.

Gaeta A, Hider RC (2005) The crucial role of metal ions in neurodegeneration: the basis for a promising therapeutic strategy. $\mathrm{Br} \mathrm{J}$ Pharmacol 146(8):1041-1059.

Gallant M, Rak M, Szeghalmi A, Del Bigio MR, Westaway D, Yang J, Julian R, Gough KM (2006) Focally elevated creatine detected in amyloid precursor protein (APP) transgenic mice and Alzheimer's disease brain tissue. J Biol Chem 281(1):5-8.

Gallant M (2008) Infrared microspectroscopy of focally elevated creatine in brain tissue from amyloid precursor protein (APP) transgenic mice. M. Sc. Thesis, University of Manitoba.

Gonzalez de Aguilar JL, Echaniz-Laguna A, Fergani A, Rene F, Meininger V, Loeffler JP, Dupuis L (2007) Amyotrophic lateral sclerosis: all roads lead to Rome. J Neurochem 101(5):1153-1160.

Hemmer W, Wallimann T (1993) Functional aspects of creatine kinase in brain. Dev Neurosci 15(3-5):249-260.

Ince PG, Clark B, Holton J, Revesz T, Wharton S (2008) Diseases of movement and system degenerations. In: Greenfield's Neuropathology, 8th ed. (Love S, Louis DN, Ellison DW, eds), pp. 8891030. London, UK: Hodder Arnold.

Kastyak MZ (2005) Master thesis: Zastosowanie synchrotronowej mikrospektroskopii w podczerwieni do analizy tkanek osrodkowego ukladu nerwowego czlowieka w chorobach neurodegeneracyjnych. University of Science and Technology, Krakow, Poland.

Klivenyi P, Ferrante RJ, Matthews RT, Bogdanov MB, Klein AM, Andreassen OA, Mueller G, Wermer M, Kaddurah-Daouk R, Beal
MF (1999) Neuroprotective effects of creatine in a transgenic animal model of amyotrophic lateral sclerosis. Nat Med 5:347-350.

Klivenyi P, Kiaei M, Gardian G, Calingasan NY, Beal MF (2004) Additive neuroprotective effects of creatine and cyclooxygenase 2 inhibitors in a transgenic mouse model of amyotrophic lateral sclerosis. J Neurochem 88(3):576-582.

Kong, J, Xu, Z (1998) Massive mitochondrial degeneration in motor neuronstriggers the onset of amyotrophic lateral sclerosis in mice expressinga mutant SOD1. J Neurosci 18:3241-3250.

Lunardi G, Parodi A, Perasso L, Pohvozcheva AV, Scarrone S (2006) The creatine transporter mediates the uptake of creatine by brain tissue, but not the uptake of two creatine-derived compounds. Neuroscience 142:991-997.

Mattson MP, Gleichmann M, Cheng A (2008) Mitochondria in neuroplasticity and neurological disorders. Neuron 60(5):748-766.

Miller L, Dumas P (2006) Chemical imaging of biological tissue with synchrotron infrared light. Biochim Biophys Acta 1758:846-857.

Mitewa M, Enchev V, Bakalova T (2002) Spectroscopic and quantum chemical study of the structure of a new paramagnetic dimeric palladium(II, III) complex with creatine. J Mol Struct 609:61-65.

Ohtsuki S, Tachikawa M, Takanaga H, Shimizu H, Watanabe M, Hosoya K, Terasaki T (2002) The blood-brain barrier creatine transporter is a major pathway for supplying creatine to the brain. J Cereb Blood Flow Metab 22:1327-1335.

Podstawka E, Swiatlowska M, Borowiec E, Proniewicz LM (2007) Food additives characterization by infrared, Raman, and surfaceenhanced Raman spectroscopies. J Raman Spectrosc 38(3):356363.

Rak M (2007a) Synchrotron infrared microspectroscopy of biological tissues: brain tissue from TgCRND8 Alzheimer's disease mice and developing scar tissue in rats. PhD. Sc.: Thesis, University of Manitoba, Winnipeg, Canada.

Rak M, Del Bigio MR, Mai S, Westaway D, Gough K (2007b) Densecore and diffuse Abeta plaques in TgCRND8 mice studied with synchrotron FTIR microspectroscopy. Biopolymers 87:207-211.

Roberts BR, Tainer JA, Getzoff ED, Malencik DA, Anderson SR, Bomben VC, Meyers KR, Karplus PA, Beckman JS (2007) Structural characterization of zinc-deficient human superoxide dismutase and implications for ALS. J Mol Biol 373(4):877-890.

Rosenfeld J, King RM, Jackson CE, Bedlack RS, Barohn RJ, Dick A, Phillips LH, Chapin J, Gelinas DF, Lou JS (2008) Creatine monohydrate in ALS: effects on strength, fatigue, respiratory status and ALSFRS. Amyotroph Lateral Scler 9(5):266-272.

Rowland LP (1998) Diagnosis of amyotrophic lateral sclerosis. J Neurol Sci 160(Suppl):S6-S24.

Sandyk R (2006) Serotonergic mechanisms in amyotrophic lateral sclerosis. Int J Neurosci 116(7):775-826.

Schlattner U, Tokarska-Schlattner M, Wallimann T (2006) Mitochondrial creatine kinase in human health and disease. Biochim Biophys Acta 1762:164-180.

Shaw PJ (2005) Molecular and cellular pathways of neurodegeneration in motor neurone disease. J Neurol Neurosurg Psychiatry 76(8):1046-1057.

Shefner JM, Cudkowicz ME, Schoenfeld D, Conrad T, Taft J, Chilton M, Urbinelli L, Qureshi M, Zhang H, Pestronk A, Caress J, Donofrio P, Sorenson E, Bradley W, Lomen-Hoerth C, Pioro E, Rezania K, Ross M, Pascuzzi R, Heiman-Patterson T, Tandan R, Mitsumoto H, Rothstein J, Smith-Palmer T, MacDonald D, Burke D (2004) A clinical trial of creatine in ALS. Neurology 63(9):1656-1661.

Spreux-Varoquaux O, Bensimon G, Lacomblez L, Salachas F, Pradat PF, Le Forestier N, Marouan A, Dib M, Meininger V (2002) Glutamate levels in cerebrospinal fluid in amyotrophic lateral sclerosis: a reappraisal using a new HPLC method with coulometric detection in a large cohort of patients. J Neurol Sci 193(2):73-78.

Strong MJ, Volkening K, Hammond R, Yang W, Strong W, LeystraLantz C, Shoesmith C (2007) TDP43 is a human low molecular weight neurofilament (hNFL) mRNA-binding protein. Mol Cell Neurosci 35(2):320-327. 
Strong MJ, Kesavapany S, Pant HC (2005) The pathobiology of amyotrophic lateral sclerosis: a proteinopathy?. J Neuropathol Exp Neurol 64(8):649-664.

Strong MJ, Yang W, Strong WL, Leystra-Lantz C, Jaffe H, Pant HC (2006) Tau protein hyperphosphorylation in sporadic ALS with cognitive impairment. Neurology 66(11):1770-1771.

Swash M, Scholz C, Vowks G, Ingram D (1988) Selective and asymmetrical vulnerability of corticospinal and spinocerebellar tracts in motor neuron disease. J Neurol Neurosurg Psychiatry 51:785-789.

Szczerbowska-Boruchowska M, Lankosz M, Ostachowicz J, Adamek D, Krygowska-Wajs A, Tomik B, Szczudlik A, Simionovici A, Bohic S (2004) Topographic and quantitative microanalysis of human central nervous system tissue using synchrotron radiation. X-Ray Spectrom 33:3-11.

Szczerbowska-Boruchowska M (2008) X-ray fluorescence spectrometry, an analytical tool in neurochemical research. X-Ray Spectrom 37:21-31.

Tarnopolsky MA, Safdar A (2008) The potential benefits of creatine and conjugated linoleic acid as adjuncts to resistance training in older adults. Appl Physiol Nutr Metab 33(1):213-227.

Thomzig A, Spassov S, Friedrich M, Naumann D, Beekes M (2004) Discriminating scrapie and bovine spongiform encephalopathy isolates by infrared spectroscopy of pathological prion protein. JBC 279(32):33847-33854.

Tomik B, Chwiej J, Szczerbowska-Boruchowska M, Lankosz M, Wójcik S, Adamek D, Falkenberg G, Bohic S, Simionovici A, Stegowski Z, Szczudlik A (2006) Implementation of X-ray fluores- cence microscopy for investigation of elemental abnormalities in amyotrophic lateral sclerosis. Neurochem Res 4:321-331.

Trushina E, McMurray CT (2007) Oxidative stress and mitochondrial dysfunction in neurodegenerative diseases. Neuroscience 145: 1233-1248.

Watzel B, Speer O, Zanolla E, Eriksson O, Bernardi P, Wallimann T (2002) Novel mitochondrial creatine transport activity: implications for intracellular creatine compartments and bioenergetics. J Biol Chem 277:37503-37511.

Wilson CM, Grace GM, Munoz DG, He BP, Strong MJ (2001) Cognitive impairment in sporadic ALS: a pathologic continuum underlying a multisystem disorder. Neurology 57(4):651-657.

Wood JD, Beaujeux TP, Shaw PJ (2003) Protein aggregation in motor neurone disorders. Neuropathol Appl Neurobiol 29(6): $529-545$.

Xiao S, Tjostheim S, Sanelli T, McLean JR, Horne P, Fan Y, Ravits J, Strong MJ, Robertson J (2008) An aggregate-inducing peripherin isoform generated through intron retention is upregulated in amyotrophic lateral sclerosis and associated with disease pathology. J Neurosci 28(8):1833-1840.

Yang W, Sopper MM, Leystra-Lantz C, Strong MJ (2003) Microtubuleassociated tau protein positive neuronal and glial inclusions in ALS. Neurology 61:1766-1773.

Zecca L, Zucca FA, Wilms H, Sulzer D (2003) Neuromelanin of the substantia nigra: a neuronal black hole with protective and toxic characteristics. Trends Neurosci 26:578-580. 